\title{
Macrodoelmatigheid Bachelor in Circular Engineering (CE) Universiteit Maastricht
}

\author{
Citation for published version (APA): \\ Cörvers, F., \& van Wetten, S. (2021). Macrodoelmatigheid Bachelor in Circular Engineering (CE) \\ Universiteit Maastricht. ROA. ROA Technical Reports No. 2019-003 \\ https://doi.org/10.26481/umarot.2019003
}

Document status and date:

Published: 13/09/2021

DOI:

10.26481/umarot.2019003

Document Version:

Publisher's PDF, also known as Version of record

\section{Please check the document version of this publication:}

- A submitted manuscript is the version of the article upon submission and before peer-review. There can be important differences between the submitted version and the official published version of record.

People interested in the research are advised to contact the author for the final version of the publication, or visit the DOI to the publisher's website.

- The final author version and the galley proof are versions of the publication after peer review.

- The final published version features the final layout of the paper including the volume, issue and page numbers.

Link to publication

\footnotetext{
General rights rights.

- You may freely distribute the URL identifying the publication in the public portal. please follow below link for the End User Agreement:

www.umlib.nl/taverne-license

Take down policy

If you believe that this document breaches copyright please contact us at:

repository@maastrichtuniversity.nl

providing details and we will investigate your claim.
}

Copyright and moral rights for the publications made accessible in the public portal are retained by the authors and/or other copyright owners and it is a condition of accessing publications that users recognise and abide by the legal requirements associated with these

- Users may download and print one copy of any publication from the public portal for the purpose of private study or research.

- You may not further distribute the material or use it for any profit-making activity or commercial gain

If the publication is distributed under the terms of Article $25 \mathrm{fa}$ of the Dutch Copyright Act, indicated by the "Taverne" license above, 


\section{Maastricht University $\&$ ROA}

Macrodoelmatigheid Bachelor in

Circular Engineering (CE) Universiteit Maastricht

Frank Cörvers

Sanne van Wetten

\section{ROA Technical Report}

ROA-TR-2019/3

Researchcentrum voor Onderwijs en Arbeidsmarkt | ROA

Research Centre for Education and the Labour Market / ROA 


\title{
Macrodoelmatigheid Bachelor in Circular Engineering (CE) Universiteit Maastricht
}

\author{
Frank Cörvers \\ Sanne van Wetten
}

ROA-TR-2019/3

Juli 2019

Research Centre for Education and the Labour Market Maastricht University

P.O. Box 616, 6200 MD Maastricht, The Netherlands

$\mathrm{T}+31433883647 \mathrm{~F}+31433884914$

secretary-roa-sbe@maastrichtuniversity.nl www.roa.nl 


\section{Inhoud}

\section{Bladzijde}

Resumé

1 Inleiding 1

2 Beschrijving bachelorprogramma Circular Engineering (CE) 2

3 Tabellen 3

3.1 Marktomvang voor de CE 3

3.2 Potentieel voor doorstroom in MA vervolgopleidingen vanuit CE 4

3.3 De arbeidsmarktkansen van vervolgopleidingen van CE en aan CE verwante bacheloropleidingen 5

4 Interviews $\quad 9$ 


\section{Resumé}

* Dit werkdocument verkent de macrodoelmatigheid van een beoogde bacheloropleiding Circular Engineering (CE) aan de Faculty of Science and Engineering (FSE) van de Universiteit Maastricht. Daartoe is gekeken naar de marktomvang van verwante opleidingen, de potentiële uitstroom naar relevante vervolgopleidingen in de masterfase en de arbeidsmarktkansen van afgestudeerden van deze vervolgopleidingen en van vergelijkbare bacheloropleidingen. Dit laatste is gedaan door de huidige en toekomstige arbeidsmarktpositie van verwante (vervolg)opleidingen van de bacheloropleiding CE in te schatten en door interviews te houden met contactpersonen uit het werkveld.

* De beoogde bacheloropleiding CE leidt op tot een ingenieur met een sterke technische basis, gecombineerd met kennis van de natuurwetenschappen en wiskunde. In de opleiding is er aandacht voor de reductie en eliminatie van de ecologische voetafdruk van producten, processen en diensten, waarbij de volledige lifecycle in beschouwing wordt genomen en integraal wordt geoptimaliseerd. Bovendien leren studenten dat de maatschappij nadrukkelijk meekijkt en invloed heeft op dit proces en de acceptatie van eventuele (deel)oplossingen. De circulaire ingenieur heeft een solide basis in de techniek, met name in chemische technologie, biotechnologie of technische natuurkunde, maar kan ook over grenzen heen kijken en verbindingen leggen tussen academische disciplines, bedrijven en de maatschappij, om de duurzaamheidstransitie te faciliteren en te versnellen.

* De FSE heeft een inventarisatie gemaakt van de aan de bachelor CE verwante bacheloropleidingen. Op basis van gegevens van DUO is bepaald hoe de studentenaantallen voor deze opleidingen zich hebben ontwikkeld als indicatie voor de marktomvang. Voor het totaal aantal ingeschreven studenten blijkt dat de marktomvang voor de CE tussen 2014 en 2018 is gestegen van bijna 4.200 naar bijna 4.800 studenten. Dit blijkt voor de meeste verwante opleidingen het geval te zijn. Ook bij de eerstejaarsstudenten en bij de gediplomeerden van deze opleidingen is er een stijging te zien.

* Tevens is er door de FSE een inventarisatie gemaakt van de masteropleidingen die kunnen dienen als vervolgopleiding voor de CE. Het totaal aantal eerstejaars van deze opleidingen is aanzienlijk gestegen, namelijk van ruim 700 in 2014 naar bijna 1.000 in 2018, wat een indicatie geeft van de grootte van de potentiële doorstroom van aan CE verwante opleidingen naar de masterfase van relevante vervolgopleidingen voor CE.

* De arbeidsmarktsituatie van gediplomeerden van de masteropleidingen was in 2017 over het algemeen goed. De werkloosheid onder afgestudeerden van relevante masteropleidingen als vervolg op de bachelor CE was met $2 \%$ beduidend lager dan gemiddeld. Ook werken er relatief veel afgestudeerden van deze opleidingen in een baan op het niveau van hun opleiding. Wel duurt het iets langer voordat men een eerste baan gevonden heeft en is het uurloon wat lager.

* De arbeidsmarktperspectieven van afgestudeerden in 2022 zien er wat betreft aan CE verwante bacheloropleidingen van het hbo en voor de relevante vervolgopleidingen in de masterfase goed tot zeer goed uit, en voor enkele opleidingen redelijk. Voor afgestudeerden van de meer technische georiënteerde richtingen van het hbo en wo zijn de arbeidsmarktperspectieven in Nederland en Zuid-Limburg goed tot zeer goed.

- De bacheloropleiding Circular Engineering wordt door de gesprekspartners in het werkveld in hoge mate gewaardeerd door de nieuwe combinaties van disciplines en doordat ze aansluit bij de ontwikkelingen die in het werkveld en de maatschappij spelen. De aandacht voor duurzaamheid en circulariteit wordt als waardevol voor bedrijven beschouwd.

* De gesprekspartners geven aan dat er zowel kwantitatieve als kwalitatieve tekorten zijn van afgestudeerden aan CE-gerelateerde richtingen: Er worden niet voldoende mensen opgeleid, en de inhoud van de opleidingen is vaak monodisciplinair. Bedrijven proberen daardoor steeds vaker ook weer eigen trainingen op te zetten, maar daarvoor ontbreekt het opleidingsvermogen van (productie)bedrijven.

* De opleiding CE is cruciaal voor de economische ontwikkeling van Zuid-Limburg. Er is nu een keuzemoment om bij te dragen aan de klimaattransitie door te investeren in de duurzame in plaats van de klassieke chemie. Als die keuze niet gemaakt wordt, is er een risico op een tweede kolenmijn-scenario voor de regio. 


\section{Inleiding}

De Faculty of Science and Engineering (FSE) streeft naar een uitbreiding van het opleidingsaanbod van de Universiteit Maastricht met een aantal bèta-opleidingen. In het kader van het macrodoelmatigheidsdossier heeft de FSE het Researchcentrum voor Onderwijs en Arbeidsmarkt (ROA) opdracht gegeven voor het uitvoeren van een verkenning van de macrodoelmatigheid van de bacheloropleiding Circular Engineering (CE). Deze opleiding leidt een ingenieur op met een sterke technische basis, gecombineerd met kennis van de natuurwetenschappen en wiskunde. De circulaire ingenieur heeft een solide basis in de techniek, met name in chemische technologie, biotechnologie of technische natuurkunde, maar kan ook over grenzen heen kijken en verbindingen leggen tussen academische disciplines, bedrijven en de maatschappij, om de duurzaamheidstransitie te faciliteren en te versnellen.

Voor de analyse van de macrodoelmatigheid van de bacheloropleiding Circular Engineering (CE) heeft de FSE aan het ROA verstrekt:

*en beschrijving van de inhoud van de bacheloropleiding;

* De opleidingsnamen en Croho-codes van verwante bacheloropleidingen in het wo en hbo;

* De opleidingsnamen en Croho-codes van bacheloropleidingen in het hbo en wo die als vervolgopleiding voor CE kunnen dienen;

- De namen van contactpersonen die goed zijn ingevoerd in het werkveld en die het nut en de noodzaak van de bacheloropleiding CE kunnen beoordelen.

Aan de hand van deze lijsten heeft het ROA voor de bacheloropleiding CE de volgende gegevens verzameld:

* Het aantal ingeschreven studenten, eerstejaars studenten en gediplomeerden van aan de CE verwante bacheloropleidingen in het wo op basis van DUO-gegevens van het ministerie van OCW. Een terugblik op de aantallen studenten en gediplomeerden van de laatste vijf jaar geeft een indicatie van de marktomvang voor de CE;

* Het aantal eerstejaarsstudenten van opleidingen in het wo die als vervolgopleiding voor de CE kunnen dienen op basis van DUO-gegevens van het ministerie van OCW. Een terugblik op deze aantallen van de laatste vijf jaar geeft een indicatie van de potentiële doorstroom naar de masteropleidingen als vervolg op de bacheloropleiding CE;

* De arbeidsmarktkansen van aan de CE verwante bacheloropleidingen en van de relevante vervolgopleidingen voor de masterfase na het afronden van de CE zijn verkend door gebruik te maken van de Nationale Alumni Enquête (NAE) en de arbeidsmarktperspectieven voor de middellange termijn in het Arbeidsmarktinformatiesysteem (AIS) van het ROA.

In de volgende paragraaf volgt een beschrijving van de bacheloropleiding CE. In paragraaf 3 zijn de tabeluitkomsten van de gegevensverzameling weergegeven. In paragraaf 4 staat een samenvatting van de interviews met de contactpersonen in het werkveld. De samenvattende conclusies zijn weergegeven in het Resumé aan het begin van dit rapport. 


\section{Beschrijving bachelorprogramma Circular Engineering (CE)}

De bachelor Circular Engineering is een technische opleiding die er op gericht is om de ingenieurs van de toekomst op te leiden die vorm gaan geven aan onze circulaire economie. Gezien de duurzaamheidtransitie naar een circulaire economie is er een grote maatschappelijke en economische behoefte aan een nieuwe type ingenieur, de circulaire ingenieur.

De circulaire ingenieur heeft een solide basis in de techniek, met name in chemische technologie, biotechnologie of technische natuurkunde, maar kan ook over grenzen heen kijken en verbindingen leggen tussen academische disciplines, bedrijven en de maatschappij, om deze transitie te faciliteren en te versnellen.

Deze circulaire ingenieur is een specialist op het gebied van duurzaamheid. Zowel in de ontwikkeling van modellen, activiteiten en technologieën om de maatschappij en industrie circulair te maken, als het ontwerp en de ontwikkeling van duurzame producten zelf, met de bijbehorende grondstoffen, energie en end-of-life problematiek en oplossingen.

De Bachelor Circular Engineering leidt een ingenieur op met een sterke technische basis, gecombineerd met kennis van de natuurwetenschappen en wiskunde. Daarnaast leren studenten dat het alleen mogelijk is om de ecologische voetafdruk van producten, processen en diensten te reduceren of zelfs te elimineren, als de volledige lifecycle in beschouwing wordt genomen en integraal wordt geoptimaliseerd. Bovendien leren studenten dat de maatschappij nadrukkelijk meekijkt en invloed heeft op dit proces en de acceptatie van eventuele (deel)oplossingen. Studenten stromen uit op drie algemene uitstroomprofielen mogelijk: chemische technologie, biotechnologie en technische natuurkunde. 


\section{Tabellen}

\subsection{Marktomvang voor de CE}

\section{Tabel 1}

Totaal aantal ingeschreven studenten in de laatste 5 jaar (2014-2018) in aan de CE verwante BA-opleidingen

\begin{tabular}{lrrrrrr} 
CE verwante BA-opleiding & Croho & $\mathbf{2 0 1 4}$ & $\mathbf{2 0 1 5}$ & $\mathbf{2 0 1 6}$ & $\mathbf{2 0 1 7}$ & 2018 \\
\hline Advanced Technology & 50002 & 260 & 248 & 237 & 239 & 247 \\
\hline Biotechnologie & 56841 & 247 & 298 & 368 & 368 & 364 \\
Environmental Sciences & 56283 & 101 & 109 & 138 & 167 & 209 \\
Life Science and Technology & 56286 & 844 & 942 & 430 & 437 & 467 \\
Scheikundige Technologie & 56960 & 582 & 641 & 670 & 692 & 764 \\
Applied Earth Sciences & 56959 & 333 & 357 & 331 & 303 & 234 \\
Technische Innovatiewetenschappen & 56265 & 358 & 417 & 468 & 494 & 567 \\
Applied Physics & 56962 & 1.464 & 1.544 & 1.727 & 1.770 & 1.927 \\
Subtotaal & & 4.189 & 4.556 & 4.369 & 4.470 & 4.779
\end{tabular}

Bron: DUO; peildatum 01-10-2018

\section{Tabel 2}

Instroom totaal aantal eerstejaarsstudenten in de laatste 5 jaar (2014-2018) in aan de CE verwante BA-opleidingen

\begin{tabular}{lrrrrrr} 
CE verwante BA-opleiding & Croho & $\mathbf{2 0 1 4}$ & $\mathbf{2 0 1 5}$ & $\mathbf{2 0 1 6}$ & $\mathbf{2 0 1 7}$ & 2018 \\
\hline Advanced Technology & 50002 & 80 & 67 & 67 & 64 & 69 \\
\hline Biotechnologie & 56841 & 72 & 101 & 122 & 88 & 93 \\
Environmental Sciences & 56283 & 32 & 27 & 51 & 53 & 75 \\
Life Science and Technology & 56286 & 219 & 292 & 92 & 131 & 142 \\
Scheikundige Technologie & 56960 & 219 & 224 & 217 & 250 & 271 \\
Applied Earth Sciences & 56959 & 99 & 79 & 70 & 63 & 32 \\
Technische Innovatiewetenschappen & 56265 & 132 & 120 & 120 & 136 & 174 \\
Applied Physics & 56962 & 498 & 443 & 542 & 479 & 509 \\
Subtotaal & & 1.351 & 1.353 & 1.281 & 1.264 & 1.365 \\
Bron: DUO; peildatum 01-10-2018 & & & & & &
\end{tabular}




\section{Tabel 3}

Uitstroom: Totaal aantal gediplomeerden in de laatste 5 jaar (2013-2017) in aan de CE verwante BA-opleidingen

\begin{tabular}{lrrrrrr} 
CE verwante BA-opleiding & Croho & $\mathbf{2 0 1 3}$ & $\mathbf{2 0 1 4}$ & $\mathbf{2 0 1 5}$ & $\mathbf{2 0 1 6}$ & $\mathbf{2 0 1 7}$ \\
\hline Advanced Technology & 50002 & 45 & 56 & 57 & 40 & 38 \\
Biotechnologie & 56841 & 45 & 45 & 40 & 56 & 83 \\
Environmental Sciences & 56283 & 25 & 19 & 22 & 24 & 30 \\
Life Science and Technology & 56286 & 154 & 162 & 192 & 102 & 111 \\
Chemical Engineering & 56960 & 70 & 92 & 122 & 133 & 145 \\
Applied Earth Sciences & 56959 & 40 & 35 & 52 & 85 & 75 \\
Technische Innovatiewetenschappen & 56265 & 25 & 48 & 46 & 78 & 98 \\
Applied Physics & 56962 & 209 & 222 & 226 & 276 & 293 \\
Subtotaal & & 613 & 679 & 757 & 794 & 873
\end{tabular}

Bron: DUO; peildatum 01-10-2018

\subsection{Potentieel voor doorstroom in MA vervolgopleidingen vanuit CE}

\section{Tabel 4}

Het totaal aantal eerstejaarsstudenten in de laatste 5 jaar (2014-2018) in MA-opleidingen die als vervolgopleiding voor de bachelor CE kunnen dienen

$\begin{array}{lrrrrrr}\text { CE vervolg MA-opleiding } & \text { Croho } & \mathbf{2 0 1 4} & \mathbf{2 0 1 5} & \mathbf{2 0 1 6} & \mathbf{2 0 1 7} & 2018 \\ \text { Applied Physics } & 60436 & 181 & 226 & 197 & 271 & 246 \\ \text { Biobased Materials } & 60955 & 0 & 6 & 8 & 12 & 15 \\ \text { Biotechnology } & 66841 & 106 & 126 & 158 & 141 & 145 \\ \text { Chemical Engineering } & 60437 & 197 & 255 & 275 & 304 & 323 \\ \text { Industrial Ecology } & 60415 & 56 & 69 & 0 & 0 & 0 \\ \text { Sustainability Science and Policy } & 69315 & 13 & 37 & 45 & 45 & 46 \\ \text { Sustainable Energy Technology } & 60443 & 147 & 179 & 163 & 195 & 196 \\ \text { Water Technology (joint degree) } & 65005 & 17 & 20 & 20 & 18 & 19 \\ \text { Subtotaal } & & 717 & 918 & 866 & 986 & 990\end{array}$

Bron: DUO; peildatum 01-10-2018 


\section{Tabel 5}

Vergelijking MA-vervolgopleidingen van CE met andere MA-opleidingen: Werkloosheidspercentage, maanden tot eerste baan, niveau van de baan en het gemiddelde uurloon, gediplomeerden anderhalf jaar na afstuderen, 2017

\begin{tabular}{lcccr} 
Opleiding & Werkloosheid (\%) & $\begin{array}{c}\text { Maanden tot } \\
\text { eerste baan }\end{array}$ & $\begin{array}{c}\text { Baan van } \\
\text { minimaal MA } \\
\text { niveau (\%) }\end{array}$ & Uurloon \\
\hline Vervolgopleiding CE & 2 & 3,04 & 69 & 15,72 \\
Andere MA opleidingen & 5 & 2,77 & 63 & 16,91
\end{tabular}

Bron: NAE 
Tabel 6

Nationale arbeidsmarktprognoses tot 2022 voor met aan CE verwante BA-opleidingen

\begin{tabular}{|c|c|c|c|c|c|c|c|c|}
\hline $\begin{array}{l}\text { Opleidings- } \\
\text { type AIS }\end{array}$ & $\begin{array}{l}\text { CE- } \\
\text { vergelijkbare } \\
\text { BA-opleiding }\end{array}$ & $\begin{array}{l}\text { CROHO } \\
\text { codes }\end{array}$ & $\begin{array}{l}\text { verwachte } \\
\text { uitbreidingsvraag } \\
\text { tot 2022; N } \\
\text { (typering) }\end{array}$ & $\begin{array}{l}\text { verwachte } \\
\text { vervangingsvraag } \\
\text { tot } 2022 ; \mathrm{N} \\
\text { (typering) }\end{array}$ & $\begin{array}{l}\text { verwachte } \\
\text { baanopeningen } \\
\text { tot 2022; N } \\
\text { (typering) }\end{array}$ & $\begin{array}{l}\text { verwachte } \\
\text { instroom van } \\
\text { schoolverlaters } \\
\text { tot } 2022 ; \mathrm{N} \\
\text { (typering) }\end{array}$ & $\begin{array}{l}\text { ITKP toekomstige } \\
\text { knelpunten } \\
\text { personeelsvoorziening } \\
\text { in 2022; N (typering) }\end{array}$ & $\begin{array}{l}\text { ITA toekomstige } \\
\text { arbeidsmarktsituatie } \\
\text { in } 2022\end{array}$ \\
\hline Hbo chemie & $\begin{array}{l}\text { Chemical } \\
\text { engineering } \\
\text { Biotechnology }\end{array}$ & $\begin{array}{l}56960 \\
56841\end{array}$ & $\begin{array}{l}2.100 \\
\text { (hoog) }\end{array}$ & $\begin{array}{l}10.100 \\
\text { (erg hoog) }\end{array}$ & $\begin{array}{l}12.200 \\
\text { (erg hoog) }\end{array}$ & $\begin{array}{l}3.100 \\
\text { (laag) }\end{array}$ & Zeer groot & Zeer goed \\
\hline \multirow{2}{*}{$\begin{array}{l}\text { Hbo } \\
\text { werktuigbouw- } \\
\text { kunde }\end{array}$} & Applied Physics & 56962 & $\begin{array}{l}5.600 \\
\text { (hoog) }\end{array}$ & $\begin{array}{l}27.000 \\
\text { (erg hoog) }\end{array}$ & $\begin{array}{l}32.600 \\
\text { (erg hoog) }\end{array}$ & $\begin{array}{l}9.800 \\
\text { (laag) }\end{array}$ & Zeer groot & Zeer goed \\
\hline & $\begin{array}{l}\text { Advanced } \\
\text { technology }\end{array}$ & 50002 & & & & & & \\
\hline $\begin{array}{l}\text { Hbo Natuur en } \\
\text { milieu }\end{array}$ & $\begin{array}{l}\text { Environmental } \\
\text { Sciences } \\
\text { Applied Earth } \\
\text { Sciences }\end{array}$ & $\begin{array}{l}56283 \\
56959\end{array}$ & $\begin{array}{l}2.900 \\
\text { (gemiddeld) }\end{array}$ & $\begin{array}{l}7.600 \\
\text { (gemiddeld) }\end{array}$ & $\begin{array}{l}10.500 \\
\text { (gemiddeld) }\end{array}$ & $\begin{array}{l}10.000 \\
\text { (gemiddeld) }\end{array}$ & Enige & Redelijk \\
\hline $\begin{array}{l}\text { Hbo } \\
\text { verpleegkunde } \\
\text { Bron: AIS ROA }\end{array}$ & $\begin{array}{l}\text { Life science and } \\
\text { technology }\end{array}$ & 56286 & $\begin{array}{l}22.000 \\
\text { (erg hoog) }\end{array}$ & $\begin{array}{l}23.700 \\
\text { (gemiddeld) }\end{array}$ & $\begin{array}{l}45.700 \\
\text { (hoog) }\end{array}$ & $\begin{array}{l}35.700 \\
\text { (gemiddeld) }\end{array}$ & Groot & Goed \\
\hline
\end{tabular}

Opmerking: De BA Sustainable innovation (innovation sciences)/technische innovatiewetenschappen (Croho 56265) ontbreekt in dit overzicht omdat deze opleiding recent gestart is en nog niet opgenomen in het AIS. 
Tabel 7

Nationale arbeidsmarktprognoses tot 2022 voor vervolg MA-opleidingen van CE






\section{Tabel 8}

Arbeidsmarktprognoses Zuid-Limburg en nationaal tot 2022 voor BA en MA

\begin{tabular}{lcc} 
Opleidingscategorie AIS & $\begin{array}{c}\text { ITA toekomstige arbeidsmarktsituatie in } 2022 \\
\text { Zuid-Limburg }\end{array}$ & Nationaal \\
\hline Hbo Techniek & Zeer goed & Goed \\
Wo Techniek & Zeer goed & Zeer goed \\
Bron: AIS ROA & &
\end{tabular}

\section{Toelichting bij Tabellen 6, 7 en 8}

$\begin{array}{ll}\text { Arbeidsmarktvariabele } & \text { Toelichting } \\ \begin{array}{ll}\text { Verwachte uitbreidingsvraag tot } & \text { Vraag naar nieuwe arbeidskrachten die ontstaat door groei van de } \\ 2022 & \text { werkgelegenheid. Als er sprake is van een werkgelegenheidsdaling, is de } \\ & \text { uitbreidingsvraag negatief. }\end{array}\end{array}$

Verwachte vervangingsvraag tot 2022

Verwachte baanopeningen tot 2022
Vervangingsvraag is de vraag naar nieuwe arbeidskrachten die ontstaat door bijvoorbeeld pensionering, (tijdelijke) uittreding vanwege zorgtaken, arbeidsongeschiktheid, beroepsmobiliteit of doorstroom naar andere opleiding.
Verwachte instroom van schoolverlaters tot 2022

ITKP toekomstige knelpunten personeelsvoorziening in 2022

ITA toekomstige arbeidsmarktsituatie in 2022
Indicator Toekomstige Knelpunten in de Personeelsvoorziening (ITKP) in 2022. Naarmate de waarde van de indicator lager wordt, zijn de verwachte knelpunten in de personeelsvoorziening groter.

Indicator Toekomstige Arbeidsmarktsituatie (ITA) in 2022. Naarmate de waarde van ITA hoger ligt, is er sprake van een slechter arbeidsmarktperspectief. 


\section{$4 \quad$ Interviews}

Ten behoeve van het macrodoelmatigheidsonderzoek voor het beoogde Bachelorprogramma Circular Engineering, hebben wij personen uit het werkveld benaderd om deel te nemen aan gesprekken over de relevantie het beoogde bachelorprogramma. De Faculty of Science and Engineering heeft hiervoor een lijst aangeleverd met negen personen die werkzaam zijn in relevante functies. Deze personen zijn via email benaderd deel te nemen aan een telefonisch gesprek. De gesprekken vonden plaats in de week van 24 juni 2019. In totaal waren vijf personen bereid deel te nemen aan een gesprek of schriftelijk vragen te beantwoorden.

Tabel 9 hieronder geeft weer welke personen hebben deelgenomen aan een gesprek, wat hun functie is en bij welk bedrijf zij werkzaam zijn. Daar waar personen genoemd zijn hebben we toestemming gekregen voor het nietanoniem verwerken van de informatie in geïntegreerde samenvatting van de interviews. De gesprekken hadden de vorm van een semi-gestructureerd interview. De vragen die de basis vormden van de gesprekken zijn als bijlage opgenomen bij dit document. Als voorbereiding op de gesprekken hebben de deelnemende personen een korte beschrijving van de beoogde opleiding via de email ontvangen.

\section{Tabel 9}

\begin{tabular}{lll}
$\begin{array}{ll}\text { Gesprekspartners } \\
\text { Naam }\end{array}$ & Functie & Bedrijf \\
\hline Anonieme gesprekspartner & Senior Researcher & $\begin{array}{l}\text { Werkzaam in chemische industrie } \\
\text { in Zuid-Limburg }\end{array}$ \\
\hline Dick Koster & $\begin{array}{l}\text { Senior Consultant Sustainable } \\
\text { Chemical Industry }\end{array}$ & TNO \\
\hline Frank Frissen & $\begin{array}{l}\text { Director Human Resources \& } \\
\text { General Affairs } \\
\text { Senior Consultant }\end{array}$ & OCl Nitrogen \\
\hline René Slaghek & $\begin{array}{l}\text { Manager Strategic Alliance and } \\
\text { Partnering }\end{array}$ & Sitech \\
\hline Jan van Vegetable Seeds
\end{tabular}

Wij geven hier een geïntegreerde samenvatting van de informatie die wij tijdens de gesprekken verkregen hebben.

De beoogde Bachelor Circular Engineering past volgens de gesprekspartners in de ontwikkelingen die in het werkveld en de maatschappij spelen. De aandacht die de opleiding geeft aan het maatschappelijk relevante thema van duurzaamheid en circulariteit wordt als waardevol erkend voor bedrijven. Frank Frissen, Director Human Resources \& General Affairs bij OCI Nitrogen, geeft aan dat veel partijen in zowel de industrie als in het onderwijs dit thema breed omarmen. Hij geeft verder aan: "Bedrijven hebben te maken met hun License to Operate. Welk mandaat hebben we vanuit de maatschappij? Vroeger zetten we heel erg in op veiligheid, maar dit is niet meer voldoende. We dienen nu ook rekening te houden met bijvoorbeeld $\mathrm{CO}^{2}$-uitstoot. Als bedrijf moet je hierin mee. [...] Een beweging naar duurzaamheid betekent dat je op een andere manier moet gaan kijken naar je operatie en met nieuwe oplossingen moet komen die verder gaan dan efficiëntie. Deze bachelor kijkt vanuit verschillende invalshoeken die nodig zijn bij het vinden van oplossingen." Dick Koster, senior consultant van TNO, onderschrijft dit: "Bedrijven worden naast de ontwikkeling van de techniek geconfronteerd met ethiek en acceptatie. Zijn bepaalde ontwikkelingen wel door de maatschappij gewenst? De ontwikkeling van producten moet passen bij wat mensen willen en niet willen. [..] niet alleen de kwaliteit van producten tellen meer mee, ook de economische en maatschappelijke waarde." Jan van den Berg van BASF Vegetable Seeds onderschrijft dit ook: "Landbouw is veranderd van een systeem waar je iets instopt, naar iets wat houdbaar moet zijn voor de toekomst. Dit enerzijds omdat de huidige manier van werken niet houdbaar is voor de toekomst, en vanuit de vraag van de consument." Ook René Slaghek van Sitech is het hiermee eens: "Belangrijk is [...] dat tegelijkertijd diverse transities moeten plaatsvinden: klimaattransitie (reductie broeikasgassen), energietransitie (van fossiel naar duurzaam), grondstoftransitie (van fossiel naar duurzaam), manufacturing transitie en een digitale transitie. Vaak zijn dat deelaspecten van een Transitie naar een circulaire economie. De hieraan gepaard gaande ontwikkeling van nieuwe en aanpassing van bestaande processen en materialen vereist een nieuwe, holistische benadering van bestaande en toekomstige uitdagingen (bijv. design for recycle, technologie-integraties, ook buiten de industrie). Dit voegt geheel nieuwe dimensies toe aan bestaande curricula op het gebied van de technologie van producten en 
processen, die zich ook uitstrekt over maatschappelijke aspecten zoals milieu en veiligheid. Op Chemelot zal bij de verschillende bedrijven vraag zijn naar goed opgeleide professionals in deze werkgebieden."

Wat de gesprekspartners vooral waarderen is het multidisciplinaire karakter van de beoogde opleiding die aansluit bij het multidisciplinaire karakter van het werken en de ontwikkelingen in de praktijk. Zoals een anonieme gesprekspartner beschrijft: "Er zijn veel ontwikkelingen waarvoor multidisciplinariteit nodig is. Het is nodig een holistische blik te hebben en niet alleen maar vanuit één veld te kunnen kijken". Deze multidisciplinariteit lijkt nodig om de transitie naar een ander bedrijfsmodel van bedrijven mogelijk te maken die houdbaar is in de toekomst. Frank Frissen stelt: "Hiervoor moeten kruisverbanden gezocht worden tussen verschillende domeinen". René Slaghek legt uit: "Ook Sitech staat aan de vooravond van grote veranderingen, waardoor de behoefte aan juist opgeleide mensen zal toenemen. Binnen Sitech werken thans meer dan 30 chemisch technologen dagdagelijks aan de ontwikkeling en optimalisatie van de chemische processen op Chemelot. Dit zal toenemen met de uitvoering van duurzaamheidsprojecten binnen de eigen organisatie en op de Brightlandssite. Op Chemelot werken zeker meer dan 100 chemisch technologen in verschillende posities van procestechnoloog en productontwikkelaars tot operationeel management zoals technical manager, productiechef en plant manager. Enerzijds blijft kennis noodzakelijk van complexe chemische processen, troubleshooting, probleem-oplossen, procesveiligheid, procesbesturing, etc. en basisvaardigheden met betrekking tot management principes. Anderzijds wordt kennis noodzakelijk om daarmee zulke nieuwe complexe systemen te kunnen creëren." Echter, het integreren van het thema circulariteit heeft wellicht minder waarde voor bedrijven die een transitie naar een verdienmodel waarin circulariteit reeds is geïntegreerd al hebben gemaakt. Jan van den Berg van BASF Vegetable Seeds geeft aan: "Het is voor ons bedrijf niet echt nodig iets af te weten over sustainability, dit zit sowieso al in de aard van onze activiteiten."

Vaardigheden die verder als belangrijk worden genoemd zijn stewardship, goede communicatievaardigheden in een internationale omgeving, inhoudelijke kennis, een brede blik en entrepreneurship. Voor bedrijven is het bovendien van belang dat afgestudeerden een goede voorbereiding op het werken in een bedrijf krijgen en leert rekening te houden met bedrijfsbelangen. Contact met de praktijk of het behandelen van een businesscase kan hieraan bijdragen.

De gesprekspartners geven aan dat er zowel kwantitatieve als kwalitatieve tekorten zijn van afgestudeerden aan CE-gerelateerde richtingen: Er worden niet voldoende mensen opgeleid, en de inhoud van de opleidingen is vaak monodisciplinair. Dick Koster geeft aan dat de mensen die nu instromen bij bedrijven vaak niet de juiste gecombineerde vaardigheden hebben: "Er zijn geen specifieke opleidingen die de klimaattransitie mogelijk maken. Mensen die vanaf begin af aan de technologie beheersen maar ook de maatschappelijke relevantie inzien, daar zijn er maar weinig van, en daar zijn er meer van nodig." Frank Frissen en René Slaghek geven aan dat er mede tekorten ontstaan door het uitvloeien van personeel dat met pensioen gaat, waarbij de instroom van nieuw personeel achterblijft. Frank Frissen geeft verder aan dat bedrijven door de kwantitatieve en kwalitatieve tekorten steeds vaker ook weer eigen trainingen opzetten. René Slaghek geeft aan dat het opleidingsvermogen van (productie)bedrijven om plaatsvervangend op te leiden tekort schiet.

Uit de gesprekken blijkt ook dat de heersende mening is dat een meer gevarieerd aanbod van technische studies, waaronder een programma als Circular Engineering, bij kan dragen aan de economische ontwikkeling van ZuidLimburg. René Slaghek geeft aan dat opleidingen nodig zijn om de continuïteit van bedrijvigheid mogelijk te kunnen maken: "Chemelot heeft grote economische waarde voor Limburg en levert producten die nog lange tijd door de maatschappij worden verlangd. Continuïteit van de bedrijvigheid is daarom van groot belang. [...] Dit vergt [...] goed opgeleide mensen die de uitstroom van de huidige grote groep werknemers tussen de 50 en 67 jaar kunnen opvangen." Ook Dick Koster is het hiermee eens en ziet een rol en kans voor de Universiteit Maastricht: "Dat zou voor de economische ontwikkeling in Zuid-Limburg erg belangrijk zijn. Er is nu een keuzemoment om dit ook te gaan doen: men kan ervoor keizen om bij te dragen aan de klimaattransitie. Als die keuze niet gemaakt wordt, loop je het risico op een tweede kolenmijn-scenario. In Zuid-Limburg is het potentieel aanwezig om een soort Sillicon Valley te worden voor de klimaattransitie. De productiecapaciteit is aanwezig om dit mogelijk te maken. Een goed voorbeeld is ASML; dit bedrijf is ontstaan uit de R\&D van Philips. Dit onderdeel is verkocht door een management buy-out 30 jaar geleden. Zo'n zelfde potentieel is er ook voor Chemelot in Zuid-Limburg. Nederland heeft sowieso een bijzondere positie door de bestaande infrastructuur inclusief de Rotterdamse haven, en omdat hi-tech gecombineerd wordt met chemie wat maatschappelijk gedreven is. Er is veel geïnvesteerd om leidend te worden in de klassieke chemie; nu is er een kans om leidend te worden in de duurzame chemie. Dit zal dan ook weer een 
aantrekkingskracht vormen voor internationaal talent. De manier van opleiden en zakendoen moet op een andere manier vormgegeven worden om dit mogelijk te maken. Daar kan Universiteit Maastricht een mooie rol in vervullen. Er zijn natuurlijk ook andere universiteiten die kandidaat zijn voor een dergelijke rol, maar die hebben al sterk een bèta-richting en liggen al meer vast in wat zij doen. Dit maakt ze minder flexibel. Hier kan Maastricht op inspelen: alfa en gamma is er al en kan gecombineerd worden met beta. Dit kan ervoor zorgen dat er binnen 10 jaar een leidende positie gecreëerd wordt." 